Cristiane Batista Andrade ${ }^{\mathrm{a}}$ (iD) https://orcid.org/0000-0003-1441-9171

Simone Gonçalves Assis ${ }^{\mathrm{a}}$

(iD https://orcid.org/0000-0001-5460-6153

${ }^{a}$ Fundação Oswaldo Cruz, Escola Nacional de Saúde Pública, Departamento de Estudos sobre Violência Jorge Carelli. Rio de Janeiro, RJ, Brasil.

Contato:

Cristiane Batista Andrade

E-mail:

cristianeandrade@fiocruz.br

Os autores declaram que o trabalho não foi subvencionado e que não há conflitos de interesses.

Os autores informam que o trabalho não é baseado em tese ou dissertação e não foi apresentado em reuniões científicas.

\section{Assédio moral no trabalho, gênero, raça e poder: revisão de literatura}

\author{
Workplace bullying, gender, race and power: a review
}

\section{Resumo}

Introdução: o assédio moral no trabalho (AMT) é considerado violência baseada em humilhações, agressões, psicoterror e abusos de poder que interferem na saúde dos trabalhadores e em suas trajetórias profissionais. Objetivo: analisar as produções científicas brasileiras sobre AMT nas áreas de saúde e educação considerando as relações de gênero, poder e raça. Métodos: revisão integrativa utilizando as bases de dados SciELO, BVS-Regional, PubMed, Scopus e Web of Science. Foram encontradas 249 produções publicadas de 2006 a 2016. Após análise, foram selecionados 20 artigos. Resultados: há carência de estudos que tenham o gênero e a raça como categorias centrais; as pesquisas apontam a necessidade de investigações sobre o assédio sexual vivenciado pelas mulheres; a organização, as condições de trabalho e as relações de poder foram apontadas como centrais nas vivências do AMT. Conclusão: os achados reiteraram a influência do AMT na saúde do(a) trabalhador(ra), na sua vida familiar e no desenvolvimento da sua carreira e indicam a necessidade de integrar às investigações científicas as categorias de raça e gênero. Recomenda-se desenvolver programas e instrumentos legais específicos para prevenir a violência ocupacional, a violência de gênero e o racismo.

Palavras-chave: trabalho; saúde; educação; assédio moral no trabalho; saúde do trabalhador.

\begin{abstract}
Introduction: workplace bullying (WB) is considered violence based on humiliation, aggressions, psychological terror and abuse of power that interferes with workers' health and the course of their careers. Objective: to analyze Brazilian scientific production on WB within the Health and Education fields considering gender, race and power relations. Method: integrative review using SciELO, Virtual Health Library-Regional Portal, PubMed, Scopus and Web of Science databases. After analysis of 249 studies, published from 2006 to 2016, 20 articles were selected. Results: there is shortage of research that has gender and race as central categories; the studies points at the need for investigations into sexual harassment experienced by women; organization, working conditions and power relations were pointed out as central to the WB experiences. Conclusion: the findings reiterated the influence of WB on workers' health, their family life and career development, and indicated the need to have the race and gender categories integrated into scientific investigations. Preventive programs and specific laws are recommended to avoid occupational and gender violences, and racism.
\end{abstract}

Keywords: work; health; education; workplace mobbing; occupational health. 


\section{Introdução}

A acumulação flexível originada da crise do capital na década de 1970 e as transformações advindas da divisão internacional do trabalho nos anos 1990 acentuaram a exploração da força de trabalho: baixos salários, diminuição da proteção trabalhista, intensificação do trabalho, jornadas extensas e exaustivas, novas formas de organização das atividades produtivas, aumento da informalidade, flexibilização da legislação trabalhista e precarização do trabalho e do modo de viver dos(as) trabalhadores(as). Do ponto de vista da saúde do trabalhador, aumentaram os acidentes de trabalho, as mortes, as lesões osteomusculares e os transtornos mentais ${ }^{1}$.

Neste cenário, Dejours e Bègue ${ }^{2}$ apontam a preocupação com os suicídios relacionados ao trabalho, vistos como reação extrema às pressões vivenciadas pelos trabalhadores. O esgotamento profissional pode ser resultado da precarização e da intensificação laboral, embora seja difícil estabelecer um nexo causal direto. É neste contexto de mudanças no mundo do trabalho que trabalhadores(as) têm sofrido com violências que atingem todos os setores e categorias profissionais, em países desenvolvidos ou não, trazendo desigualdades, discriminações, estigmatizações e conflitos para as relações laborais, além de problemas de saúde e abandono do trabalho. Entre essas violências estão as agressões, os insultos, as intimidações, o assédio moral e sexual e o racismo ${ }^{3}$.

O assédio moral como violência no trabalho é definido por Marie-France Hirigoyen ${ }^{4}$ como "toda e qualquer conduta abusiva manifestando-se sobretudo por comportamentos, palavras, atos, gestos, escritos que possam trazer dano à personalidade, à dignidade ou à integridade física ou psíquica de uma pessoa, pôr em perigo seu emprego ou degradar o ambiente de trabalho" (p. 65). Considerado uma violência perversa, o assédio moral engloba a desqualificação, o isolamento, a atribuição de tarefas de menor valor, a indução ao erro, o assédio sexual, a exclusão, as mudanças de horários e de atividades sem prévio aviso, abusos de poder etc. Para Hirigoyen, o psicoterror gera hostilidade e maldade, ocasionando o aniquilamento psíquico que pode levar ao suicídio. Muito mais que uma relação conflituosa, o assédio moral no trabalho (AMT) está relacionado a abusos hierárquicos, à dominação e à intencionalidade ${ }^{5}$.

Os riscos do AMT são muitas vezes invisíveis, visto que sua violência nem sempre é física - frequentemente, são as palavras e os gestos que tiram as forças das pessoas. No AMT, ocorrem também perseguições e pressões constantes, com agravos à dignidade e ao direito a um trabalho que proporcione saúde física e mental. É difícil conceituá-lo em decorrência da sua complexidade e de suas múltiplas dimensões ${ }^{6}$. Soares e Oliveira ${ }^{7}$, apoiados em diversos autores, apresentam como consequências do assédio moral quadros de depressão e ansiedade, dificuldades no sono, estresse pós-traumático e suicídio.

A partir desta perspectiva, autores brasileiros como Barreto e Heloani ${ }^{8}$ afirmam que "o assédio moral é um processo complexo, [e] devemos evitar conceitos simplistas, inaptos ou inadequados sobre o que é ou não é, em uma vã tentativa de dar conta de todas as variáveis, geradas de uma constelação de danos morais que atingem a dignidade, a saúde, a liberdade e a personalidade, impondo dor e violando direitos fundamentais" (p. 557). O consenso são as implicações para a saúde e a vida da classe trabalhadora: humilhações, tortura psicológica, insegurança e medos. Como central para o entendimento do AMT, Barreto e Heloani trazem à tona a intolerância social, considerada histórica, social e produto da cultura. A intolerância se concretiza nas práticas de discriminações, nos preconceitos, nas humilhações, e é expressa pelo racismo que impõe dificuldades de acesso às políticas de educação e de inserção no mercado de trabalho para um grande contingente de negros e pardos ${ }^{8}$.

As relações de poder são cruciais para o entendimento do AMT. Neste aspecto, destaca-se a produção de Elias e Scotson ${ }^{9}$, fundamentada em uma perspectiva social e histórica. As formações sociais dos grupos, suas tensões e seus conflitos são vividos e experienciados por todos, em qualquer posição social. As segregações, as ameaças às posições sociais, os vínculos afetivos, as forças coercitivas, as hierarquias e os status são importantes para se entender como as relações de poder podem fazer parte das configurações entre as pessoas. Trata-se, portanto, de partir da experiência para entender como os sujeitos lidam com as hierarquias e o status no ambiente de trabalho, buscando apreender como se relacionam com as forças coercitivas entre os grupos e também com os abusos de poder.

A dimensão de gênero é outro tema fundamental, pois as relações sociais estão associadas à divisão sexual do trabalho e perpetuam as desigualdades entre homens e mulheres na sociedade capitalista ${ }^{10}$. Hirata e Kergoat ${ }^{11}$ apontam dois princípios fundamentais para a análise das relações sociais de gênero. O primeiro é o entendimento do processo de hierarquização em que o trabalho masculino é mais valorizado que o feminino. O segundo relaciona-se à separação entre atividades consideradas femininas e atividades consideradas masculinas: "A divisão sexual do trabalho é a forma de divisão do trabalho social decorrente das relações sociais entre os sexos; mais do que isso, é um fator prioritário para a sobrevivência da relação social entre os sexos. Essa forma é modulada histórica e socialmente" (p. 599). Ainda 
sob este ponto de vista, os papéis sociais e históricos desempenhadas por homens e mulheres têm fundamento material, que integra as inúmeras relações de poder entre os sexos ${ }^{10}$.

A noção de consubstancialidade em Kergoat ${ }^{12}$ é importante para o estudo das relações sociais e do trabalho na perspectiva da dialética e do materialismo histórico. Para autora, o desafio é não somente entrelaçar as categorias raça, gênero e classe, mas a partir "das relações sociais que fabricam tais categorias, rastrear os processos que estão na origem da produção de grupos e pertencimentos objetivos e subjetivos" (p. 21). Nesse sentido, Bruschini e Lombardi ${ }^{13}$ pontuam, a partir de pesquisas brasileiras, as diferenciações entre homens, mulheres, brancos e negros no mercado de trabalho e nos indicadores de desemprego. As mulheres negras são mais discriminadas, desempenham trabalhos precários e ganham menores salários.

As relações de gênero são importantes para a compreensão da $\mathrm{AMT}^{7-14}$, e é preciso analisar as configurações desse tipo de violência para homens e mulheres, considerando suas consequências na vida pessoal e no trabalho. Há evidências de que as mulheres não vivenciam a violência no trabalho da mesma forma que os homens, e deve haver diferenciações no enfrentamento do AMT segundo o gênero: as mulheres procuram mais ajuda, quer seja médica ou psicológica, enquanto os homens, ao se reconhecerem como assediados, podem sofrer problemas com a autoidentidade masculina, visto que a virilidade é frequentemente requerida no ambiente de trabalho ${ }^{15-16}$.

Um estudo de revisão integrativa ${ }^{17}$ confirma as diferenças entre os sexos demonstrando que as mulheres são as que mais sofrem com o assédio moral. Para elas, os abusos e as agressões verbais estão nas piadas grosseiras sobre vestuários e aparência física; já para os homens, nas piadas relacionadas à virilidade, à capacidade de trabalhar e à manutenção da subsistência familiar.

Concordamos com Gaignard ${ }^{18}$, que, ao tratar do racismo no trabalho, aponta que o termo "raça" não é posto no sentido biológico, mas como relações sociais e hierárquicas expressas em discriminações raciais no ambiente laboral. Assim, há a preocupação quanto às repercussões do racismo na vida e na subjetividade dos trabalhadores e até mesmo na construção de estratégias coletivas de defesa na relação entre as atividades e a subjetividade. $\mathrm{O}$ assédio moral passa também pela discriminação racial. Um estudo de revisão integrativa ${ }^{14}$ confirma essa relação a partir de estudos ingleses que demonstram que enfermeiras estrangeiras são mais denunciadas aos conselhos profissionais, ocasionando o "isolamento social e profissional” (p. 820).
As áreas da saúde e da educação, em que o processo de feminização tem ocorrido ao longo do tempo, são hoje consideradas "guetos femininos". Na área da saúde, por exemplo, os dados censitários de 2005 mostram que as mulheres representam 61,7\% dos 709.267 profissionais de saúde de nível superior ${ }^{19}$. Na educação, os dados da Pnad de 2013 apontam que havia 418.538 (16,9\%) homens e 2.059.947 (83,1\%) mulheres nas redes municipais e estaduais de ensino ${ }^{20}$.

Este trabalho tem por objetivo analisar produções científicas brasileiras sobre AMT nas áreas de saúde e educação, considerando as relações de gênero, poder e raça.

\section{Métodos}

Partindo das categorias sociológicas de gênero e raça para a compreensão da organização do trabalho, este estudo de revisão bibliográfica integrativa ${ }^{21}$ busca compreender o AMT tendo como questão norteadora: na produção científica brasileira nas áreas de educação e saúde, as dimensões de gênero e raça estão presentes nas análises? Partindo do pressuposto de que nos últimos anos a temática do AMT tem sido objeto de estudos de pesquisadores brasileiros, a revisão integrativa permite sintetizar a produção científica nacional com pesquisas empíricas e teóricas já debatidas ${ }^{22}$.

Na primeira etapa da pesquisa, em abril de 2017, os estudos foram buscados nas seguintes bases de dados: SciELO, BVS-Regional, PubMed, Scopus e Web of Science. Os descritores e as ocorrências estão descritos na Tabela 1.

Tabela 1 Bases de dados, descritores e ocorrências

\begin{tabular}{|c|c|c|}
\hline Base de dados & Descritores & Ocorrências \\
\hline SCIELO & $\begin{array}{l}\text { ("assedio moral" OR "assedio } \\
\text { sexual" OR bullying) AND } \\
\text { (trabalh" OR laborat" OR } \\
\text { corporat" OR profission") }\end{array}$ & 113 \\
\hline BVS-Regional & $\begin{array}{l}\text { (“assedio moral” OR "assedio } \\
\text { sexual" OR bullying) AND } \\
\text { (trabalh" OR laborat" OR } \\
\text { corporat" OR profission") }\end{array}$ & 101 \\
\hline Scopus & $\begin{array}{l}\text { (TITLE-ABS-KEY(bullying OR } \\
\text { mobbing) AND TITLE-ABS- } \\
\text { KEY(workplace OR work) AND } \\
\text { TITLE-ABS-KEY(brasil* OR brazil*)) }\end{array}$ & 16 \\
\hline PubMed & $\begin{array}{l}\text { ((bullying OR mobbing) AND } \\
\text { (workplace OR work)) AND } \\
\text { (brazil* OR brasil*) }\end{array}$ & 7 \\
\hline $\begin{array}{l}\text { Web of } \\
\text { Science }\end{array}$ & $\begin{array}{l}\text { ((bullying OR mobbing) AND } \\
\text { (workplace OR work)) AND } \\
\text { (brazil* OR brasil*) }\end{array}$ & 12 \\
\hline Total & & 249 \\
\hline
\end{tabular}


Os achados foram inseridos no gerenciador de referências Zotero. Em seguida, deu-se início à leitura dos resumos e dos textos completos (quando acessíveis), visando aplicar os critérios de exclusão e inclusão ${ }^{21}$ em todo o banco de dados:

a) critérios de exclusão: artigos de revisão, ensaios e resenhas, documentos não brasileiros, teses, dissertações, livros e trabalhos de graduação, documentos oficiais e áudios, textos que não faziam menção ao AMT.

b) critérios de inclusão: artigos de estudos empíricos sobre AMT nas áreas de saúde e educação no contexto brasileiro, publicados entre 2006 e 2016. Houve duas exceções: duas revisões de literatura específicas da área da saúde (Fontes et al. ${ }^{14}$; Hagopian, Freitas e Costa ${ }^{23}$ ) foram incluídas por contribuírem para o conhecimento do estado da arte da temática. Não foi encontrada nenhuma revisão de literatura específica da área de educação.

Na Figura 1 pode-se verificar o processo de seleção dos documentos avaliados. Dos 249 documentos inicialmente encontrados nas bases de dados, 20 foram selecionados.

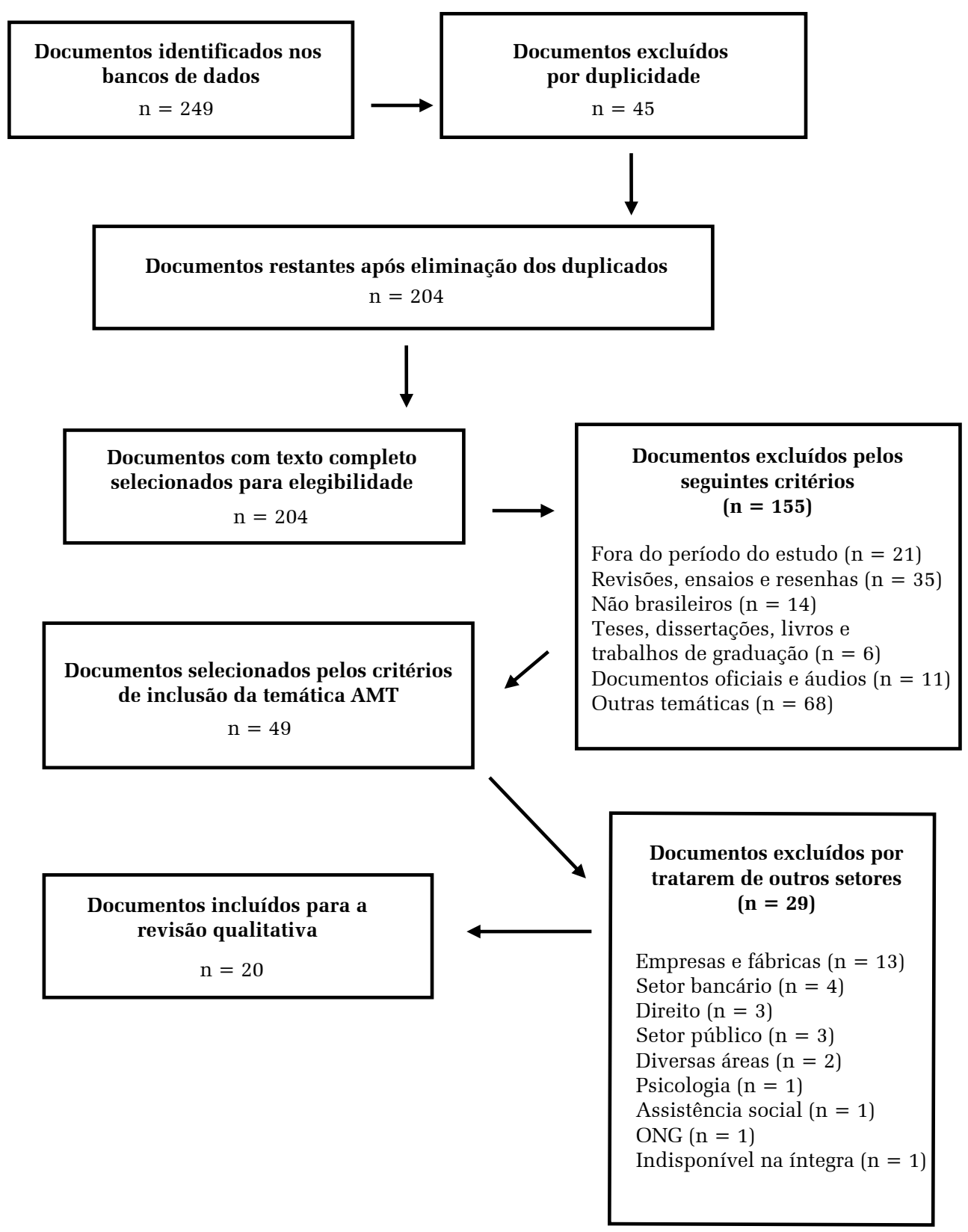

Figura 1 Fluxograma elaborado a partir das recomendações PRISMA ${ }^{24}$ 


\section{Resultados}

De acordo com Soares e Oliveira ${ }^{7}$, nas duas últimas décadas, os estudos sobre o AMT avançaram, sendo observado aumento do número de investigações que corroboram a necessidade de programas de prevenção, dados os problemas de saúde que acometem trabalhadores em distintas atividades.

Dos 20 artigos encontrados, 12 são referentes ao AMT na área da saúde e 8 na área de educação. O Quadro 1 contém os artigos selecionados, ano de publicação, objetivos da pesquisa, métodos e principais achados.

Quadro 1 Autores, ano de publicação, objetivos, métodos e principais achados das pesquisas sobre AMT na área da saúde e da educação

\begin{tabular}{|c|c|c|}
\hline \multicolumn{3}{|c|}{ Trabalhadores da saúde } \\
\hline Autores (ano) & Objetivos & Métodos e principais achados \\
\hline Cezar e Marziale ${ }^{25}$ (2006) & $\begin{array}{l}\text { Analisar a violência } \\
\text { ocupacional entre } \\
\text { trabalhadores do serviço de } \\
\text { urgência de um hospital. }\end{array}$ & $\begin{array}{l}\text { Pesquisa quantitativa; instrumento de avaliação de violência no } \\
\text { trabalho, registros de casos de violência e entrevistas. Foram } \\
\text { entrevistados } 33 \text { trabalhadores da enfermagem e } 14 \text { médicos: } 95,2 \% \\
\text { disseram ter sofrido agressões verbais; } 16,7 \% \text { dos médicos e } 30 \% \text { da } \\
\text { equipe de enfermagem relataram AMT. }\end{array}$ \\
\hline Xavier et al. ${ }^{26}(2009)$ & $\begin{array}{l}\text { Analisar o AMT no setor de } \\
\text { saúde no estado do Rio de } \\
\text { Janeiro. }\end{array}$ & $\begin{array}{l}\text { Responderam a um questionário autoaplicável } 1.569 \text { profissionais. } \\
\text { Auxiliares de enfermagem foram os que mais relataram AMT }(22,7 \%) \text {, } \\
\text { seguidos dos enfermeiros }(21,5 \%) \text {. Os agressores foram colegas, } \\
\text { supervisores e gestores }(48,7 \%) \text {. }\end{array}$ \\
\hline Villaça e Palácios ${ }^{27}$ (2010) & $\begin{array}{l}\text { Analisar o trote na } \\
\text { percepção de estudantes } \\
\text { e docentes de medicina } \\
\text { e relatar as situações de } \\
\text { violência. }\end{array}$ & $\begin{array}{l}\text { Pesquisa qualitativa; estudo de caso. Foram encontradas situações } \\
\text { de abusos verbais e físicos, casos de estelionato, agressões, } \\
\text { desqualificações, ameaças e humilhações no trote universitário. Há } \\
\text { indícios da naturalização da violência por parte dos depoentes. }\end{array}$ \\
\hline Fontes et al. ${ }^{14}(2011)$ & $\begin{array}{l}\text { Verificar os conhecimentos } \\
\text { sobre AMT na enfermagem } \\
\text { em produções nacionais e } \\
\text { internacionais. }\end{array}$ & $\begin{array}{l}\text { Foram analisadas } 18 \text { publicações através de revisão integrativa: as } \\
\text { ações de assédio incluem humilhações, depreciações, controle do } \\
\text { trabalho, exposições de críticas depreciativas etc. Interferências na } \\
\text { saúde: tristeza, depressão, desequilíbrios do sono, ansiedade, dores } \\
\text { de cabeça, medo, solidão e sintomas de estresse. }\end{array}$ \\
\hline Fontes e Carvalho ${ }^{28}$ (2012) & $\begin{array}{l}\text { Identificar as percepções } \\
\text { de enfermeiros sobre o } \\
\text { assédio moral e as variáveis } \\
\text { envolvidas, características e } \\
\text { condutas do AMT. }\end{array}$ & $\begin{array}{l}\text { Abordagem quantitativa ( } 177 \text { mulheres e } 22 \text { homens) e uso de } \\
\text { estatística descritiva: } 29,7 \% \text { dos entrevistados perceberam-se vítimas } \\
\text { de AMT; a duração média da violência foi de } 13,5 \text { meses; } 64,8 \% \\
\text { presenciaram colegas sendo vítimas de AMT. Condutas comuns: } \\
\text { "questionamento de decisões" ( } 26,1 \% \text { ) e "ataques verbais criticando } \\
\text { trabalhos realizados" (16,6\%). }\end{array}$ \\
\hline Marques et al. ${ }^{29}(2012)$ & $\begin{array}{l}\text { Conhecer a prevalência de } \\
\text { casos de AMT em residentes } \\
\text { médicos e não médicos. }\end{array}$ & $\begin{array}{l}\text { Abordagem quantitativa ( } 105 \text { residentes) com uso de questionários: } \\
41,9 \% \text { já sofreram com o assédio moral. Mulheres referiram } \\
\text { mais problemas psíquicos em decorrência do AMT. Principais } \\
\text { assediadores são preceptores e coordenadores de cursos. }\end{array}$ \\
\hline Fontes et al. ${ }^{30}(2013)$ & $\begin{array}{l}\text { Identificar o AMT entre } \\
\text { enfermeiros e determinar os } \\
\text { fatores associados. }\end{array}$ & $\begin{array}{l}\text { Abordagem quantitativa ( } 199 \text { enfermeiros): } 11,6 \% \text { foram vítimas de } \\
\text { AMT. O grupo assediado relatou sofrer agressões majoritariamente } \\
\text { de mulheres. Trabalhar no mesmo local por um período de } 1 \text { a } 3 \text { anos } \\
\text { aparece como um fator mais fortemente ligado ao AMT. }\end{array}$ \\
\hline Cahu et al. ${ }^{31}(2014)$ & $\begin{array}{l}\text { Analisar situações de AMT } \\
\text { vivenciadas por enfermeiros }\end{array}$ & $\begin{array}{l}\text { Abordagem quantitativa com } 259 \text { enfermeiros de unidades básicas } \\
\text { de saúde e hospitais. Principais situaç̃̃es de AMT relatadas: } \\
\text { manipular pessoas para assumir posicionamentos contrários aos } \\
\text { interesses do assediado }(47,4 \%) \text {, impedir o crescimento profissional } \\
(40,5 \%) \text {, falar aos gritos }(32,8 \%) \text {, ignorar a presença na frente de } \\
\text { outras pessoas }(55,2 \%) \text {. }\end{array}$ \\
\hline Nelson et al. ${ }^{32}(2014)$ & $\begin{array}{l}\text { Examinar as percepções } \\
\text { do AMT e o bem-estar } \\
\text { de profissionais de } \\
\text { enfermagem. }\end{array}$ & $\begin{array}{l}\text { Pesquisa quantitativa com } 868 \text { enfermeiros, técnicos e auxiliares } \\
\text { de enfermagem ( } 89,5 \% \text { mulheres) de } 4 \text { hospitais brasileiros. Há } \\
\text { desvalorização profissional, receio de perder o emprego, contratos } \\
\text { precários de trabalho, insegurança, vulnerabilidade e pouco apoio } \\
\text { institucional. }\end{array}$ \\
\hline
\end{tabular}

(Continua) 
Quadro 1 Continuação...

\begin{tabular}{|c|c|c|}
\hline \multicolumn{3}{|c|}{ Trabalhadores da saúde } \\
\hline Autores (ano) & Objetivos & Métodos e principais achados \\
\hline Andrade et al. ${ }^{33}$ (2015) & $\begin{array}{l}\text { Investigar as situações } \\
\text { de AMT e suas causas } \\
\text { e consequências em } \\
\text { enfermeiros da atenção } \\
\text { básica de saúde. }\end{array}$ & $\begin{array}{l}\text { Pesquisa qualitativa com } 16 \text { profissionais de enfermagem (11 } \\
\text { técnicos de enfermagem e } 5 \text { enfermeiros). Foram relatadas } \\
\text { humilhações, perseguições constantes, AMT descendente e } \\
\text { constrangimentos. Problemas de saúde relatados: febre emocional, } \\
\text { medo, tristeza, choro e depressão. }\end{array}$ \\
\hline Lima e Sousa ${ }^{34}$ (2015) & $\begin{array}{l}\text { Investigar e caracterizar } \\
\text { a violência psicológica no } \\
\text { trabalho entre equipe de } \\
\text { enfermagem, pacientes e } \\
\text { acompanhantes. }\end{array}$ & $\begin{array}{l}\text { Pesquisa quantitativa com } 124 \text { trabalhadores da área da } \\
\text { enfermagem. Foram relatadas agressões verbais (95\%), assédio moral } \\
(27 \%) \text {, assédio sexual (9\%) e discriminação racial }(9 \%) \text {. }\end{array}$ \\
\hline $\begin{array}{l}\text { Hagopian, Freitas e Costa }{ }^{23} \\
(2016)\end{array}$ & $\begin{array}{l}\text { Identificar e analisar o AMT } \\
\text { na enfermagem. }\end{array}$ & $\begin{array}{l}\text { Estudo bibliográfico por meio de revisão sistemática; análise } \\
\text { qualitativa. As autoras mostram as dificuldades no reconhecimento e } \\
\text { enfrentamento do AMT pela área da enfermagem. }\end{array}$ \\
\hline \multicolumn{3}{|c|}{ Educação } \\
\hline Autores (ano) & Objetivos & Método e principais achados \\
\hline Canen e Canen 35 (2007) & $\begin{array}{l}\text { Analisar a organização } \\
\text { do trabalho a partir do } \\
\text { multiculturalismo a fim } \\
\text { de auxiliar na gestão de } \\
\text { conflitos de uma instituição } \\
\text { de ensino superior. }\end{array}$ & $\begin{array}{l}\text { Pesquisa qualitativa; estudo de caso com enfoque na história oral. } \\
\text { Evidencia-se o respeito à diversidade cultural (gênero, raça/etnia, } \\
\text { orientação sexual, religião etc.). As lutas pelo poder nas instituições } \\
\text { podem perpassar o AMT. Importância do multiculturalismo nas } \\
\text { práticas de lideranças na gestão do trabalho. }\end{array}$ \\
\hline Caran et al..$^{36}(2010)$ & $\begin{array}{l}\text { Identificar o AMT entre } \\
\text { professores do ensino } \\
\text { superior público. }\end{array}$ & $\begin{array}{l}\text { Estudo quantitativo com } 54 \text { docentes: } 40,7 \% \text { sofreram AMT, 59,3\% } \\
\text { presenciaram colegas sendo assediados. Foram relatadas ameaças, } \\
\text { humilhações, fofocas, desqualificações, gritos, críticas e difamações. }\end{array}$ \\
\hline Campos et al. ${ }^{37}(2012)$ & $\begin{array}{l}\text { Analisar o AMT, seus riscos } \\
\text { e implicações para a saúde } \\
\text { dos servidores públicos. }\end{array}$ & $\begin{array}{l}\text { Pesquisa qualitativa; estudo de caso de uma docente com realização } \\
\text { de entrevistas, análise de documentos, anamnese e observação. } \\
\text { Houve riscos biopsicossociais à saúde e deterioração das relações } \\
\text { profissionais. }\end{array}$ \\
\hline Pinto e Paula ${ }^{38}$ (2013) & $\begin{array}{l}\text { Analisar a violência } \\
\text { interpessoal vivenciada por } \\
\text { universitários que atuaram } \\
\text { ou atuam em uma empresa } \\
\text { júnior universitária. }\end{array}$ & $\begin{array}{l}\text { Estudo qualitativo com } 20 \text { entrevistas; metodologia da história oral. } \\
\text { Observou-se a naturalização da violência por parte de assediados } \\
\text { e assediadores. O estudo analisa o assédio moral no trabalho e as } \\
\text { relações entre violência simbólica e interpessoal. }\end{array}$ \\
\hline Jacoby e Monteiro ${ }^{39}$ (2014) & $\begin{array}{l}\text { Investigar a prevalência } \\
\text { do AMT entre } \\
\text { estudantes universitários } \\
\text { trabalhadores e suas } \\
\text { características laborais e } \\
\text { biossociodemográficas. } \\
\end{array}$ & $\begin{array}{l}\text { Pesquisa quantitativa com } 457 \text { jovens da área de psicologia, } \\
\text { administração e contabilidade. Verificaram-se altos índices de } \\
\text { práticas de AMT, vistas como naturais e inerentes à organização do } \\
\text { trabalho. }\end{array}$ \\
\hline Rodrigues e Freitas ${ }^{40}(2014)$ & $\begin{array}{l}\text { Investigar e analisar } \\
\text { o AMT e as condições } \\
\text { organizacionais que } \\
\text { favorecem a sua ocorrência } \\
\text { segundo a percepção de } \\
\text { professores universitários } \\
\text { de instituições privadas. }\end{array}$ & $\begin{array}{l}\text { Pesquisa qualitativa com análise documental de } 6 \text { processos } \\
\text { trabalhistas e } 17 \text { entrevistas com professores. O AMT está } \\
\text { relacionado a questões de ordem pessoal e organizacional e à } \\
\text { competitividade. Os depoentes apontaram as influências do AMT na } \\
\text { vida familiar e no desenvolvimento da carreira. }\end{array}$ \\
\hline $\begin{array}{l}\text { Guimarães, Cançado e Lima }{ }^{41} \\
\text { (2016) }\end{array}$ & $\begin{array}{l}\text { Caracterizar um caso de } \\
\text { AMT em uma instituição } \\
\text { pública de ensino superior. }\end{array}$ & $\begin{array}{l}\text { Pesquisa qualitativa; análise documental, coleta de depoimentos de } \\
\text { envolvidos e entrevista com o servidor assediado. Foram relatados } \\
\text { assédio vertical descendente com implicações na saúde física, } \\
\text { mental e emocional e ausência de atuação do serviço de recursos } \\
\text { humanos. }\end{array}$ \\
\hline Jacoby e Monteiro ${ }^{42}$ (2016) & $\begin{array}{l}\text { Investigar o AMT entre } \\
\text { estudantes trabalhadores e } \\
\text { as relações com o bem-estar. }\end{array}$ & $\begin{array}{l}\text { Pesquisa quantitativa (457 estudantes de graduação) com uso } \\
\text { de questionário. Houve relação do AMT com o bem-estar dos } \\
\text { estudantes, com menor satisfação no trabalho e interferências nas } \\
\text { atividades laborais. }\end{array}$ \\
\hline
\end{tabular}


A seleção é composta por 2 revisões bibliográficas da literatura sobre AMT e enfermagem, 11 estudos de abordagem quantitativa e 7 de abordagem qualitativa (2 deles da área da saúde e 5 na área da educação). De maneira geral, todos os artigos conceituam o AMT como uma violência que envolve humilhações, abusos de poder, agressões verbais, sofrimentos, discriminações etc. As implicações na vida profissional e familiar e na saúde dos(as) trabalhadores(as) também são um consenso. A violência como construção histórica e social traz influências prejudiciais - físicas, psíquicas e morais - para a qualidade de vida das pessoas ${ }^{43}$.

Embora não seja considerado uma doença, o AMT pode acarretar angústias, estresse, danos psíquicos e/ou físicos, baixa da autoestima e da confiança, desestabilização e fragilização dos trabalhadores. A maioria dos artigos oriundos das áreas da saúde e da educação aponta uma série de influências na vida e na saúde da classe trabalhadora: tristeza ${ }^{14,33,37}$, baixa autoestima $^{37}$, estresse ${ }^{14}$, ansiedade ${ }^{14}$, febre emocional $^{33}$, medo $^{14,33}$, depressão ${ }^{14,33,37}$, choro $^{33}$, problemas de sono ${ }^{14}$ e ideação suicida ${ }^{37,41}$.

Das 12 publicações sobre o AMT na área da saúde, 2 são estudos empíricos na área da medicina (um sobre universitários e docentes de medicina ${ }^{27}$, outro com residentes médicos e não médicos ${ }^{29}$ ), 2 são revisões de literatura sobre enfermagem ${ }^{14,23} \mathrm{e}$ 7 são estudos empíricos com equipes de enfermagem $^{26,28,30-34}$ e apenas 1 trata da enfermagem e medicina concomitantemente ${ }^{25}$. Os achados da revisão integrativa da área da educação abarcam 1 pesquisa sobre a organização do trabalho em instituições de ensino superior ${ }^{35}, 3$ estudos sobre o trabalho de professores $^{36,37,40}, 3$ sobre estudantes ${ }^{38,39,42}$ e 1 de um bibliotecário alocado no ensino superior ${ }^{41}$. De maneira geral, todos os artigos afirmam as imbricações da saúde com o desenvolvimento profissional, justificando a necessidade de prevenção do AMT.

Os dados de Nelson et al. ${ }^{32}$, coletados em estudo com uma equipe de enfermagem, mostram a necessidade da gestão dos serviços de saúde promover ações de cuidado à saúde dos trabalhadores e desenvolver medidas de recursos humanos para o enfrentamento do AMT. Sendo o AMT considerado um abuso de poder, com humilhações e intimidações que prejudicam a trajetória profissional e a saúde dos(as) trabalhadores(as), são necessárias políticas de prevenção e coibição da violência. As ocorrências devem ser denunciadas. Para isso, é preciso que os profissionais saibam identificar o AMT e evitá-lo ${ }^{44}$.

Sobre as relações entre AMT e gênero, Fontes e Carvalho $^{28}$ encontraram maior frequência de relatos entre o sexo feminino: cerca de $30 \%$ das entrevistadas reconheciam-se como vítimas.
Por outro lado, a pesquisa de Xavier et al. ${ }^{26}$ com trabalhadores da área de saúde verificou que $18 \%$ dos homens e $16,2 \%$ das mulheres entrevistadas foram vítimas de AMT. Na pesquisa de Cezar e Marziale $^{25}$, entre os trabalhadores (médicos, enfermeiros, técnicos e auxiliares de enfermagem) que sofreram algum tipo de violência ocupacional, 55,3\% são homens e 44,7\% são mulheres.

Já o assédio sexual foi relatado por 4 pesquisas empíricas $^{25,31,33,34}$ e uma revisão de literatura ${ }^{14}$. Na pesquisa de Cezar e Marziale ${ }^{25}, 16,7 \%$ dos médicos e $30 \%$ da equipe de enfermagem disseram ter vivenciado AMT, e 25\% dos médicos disseram ter sofrido assédio sexual. Os autores reiteram que os fatores de risco para a violência ocupacional são: usuários em situações de agressividade, ausência de formação profissional para lidar com a violência, sobrecarga de trabalho, superlotação de pacientes, ambiente estressante, dentre outros ${ }^{25}$.

A pesquisa de Cahu et al. ${ }^{31}$, realizada com 259 enfermeiros de unidades básicas de saúde e hospitais, buscou analisar as situações de assédio moral. As situações mais relatadas pelos sujeitos foram: "o assediador critica seu trabalho de forma injusta e exagerada" ( $47,41 \%)$; "faz circular maldades e calúnias sobre você" (40,52\%); "fala mal de você em público" (31,3\%); "insinua e faz correr boatos de que você está com problemas de saúde (6,3\%)" (p. 153). Outro achado da pesquisa diz respeito às dificuldades impostas pelos assediadores a fim de evitar o crescimento profissional das pessoas: contestação de decisões, restrições ao direito de férias, mudanças de horários de trabalho, discriminação salarial, delegação de atividades em excesso, fornecimento de informações imprecisas e incentivo ao pedido de demissão. $\mathrm{O}$ assédio sexual foi relatado por 1,7\% dos profissionais.

O objetivo do artigo de Andrade et al. ${ }^{33}$ foi analisar o assédio moral na perspectiva de 11 técnicos de enfermagem e 5 enfermeiros que trabalham em unidades de saúde da família. Há situações de humilhações e constrangimentos que causam depressão, medo, tristeza e episódios de febre. Um caso de assédio sexual foi relatado por uma trabalhadora que presenciou uma colega sendo assediada por um médico. O estudo não abarcou a organização e as condições de trabalho como subsídios para entender o AMT.

A pesquisa de Lima e Sousa ${ }^{34}$ apontou 88 casos de violência psicológica: $95 \%$ envolveram agressão verbal, $27 \%$ assédio moral, $9 \%$ assédio sexual e $9 \%$ discriminação racial. As mulheres foram as maiores vítimas de violência psicológica (87\%).

A contribuição da revisão de literatura de Fontes et al. ${ }^{14}$ está em mostrar a importância das categorias de raça e gênero para a compreensão do assédio. As autoras apontam a relação entre AMT e assédio 
sexual, demonstrando como as mulheres são mais suscetíveis a essas violências.

O estudo do AMT entre residentes médicos e não médicos aponta que 41,9\% relatam já ter sofrido assédio, sendo as mulheres mais suscetíveis à violência no trabalho. Entre elas, 65,9\% tiveram problemas psíquicos em virtude do assédio. Os preceptores, os coordenadores da residência e os residentes mais velhos são os que mais perpetram o assédio ${ }^{29}$.

Villaça $^{27}$ et al. discutem a banalização do assédio moral e da violência nos trotes universitários do curso de medicina. Tanto professores quanto alunos relataram abusos físicos e verbais como inerentes ao trote. Os participantes mencionam agressões, desqualificações, ameaças, humilhações, estelionato e uso de álcool. Foram percebidas a individualização e a banalização da violência e a ausência de debates sobre o problema, o que reforça a necessidade de compreender as violências vivenciadas pelos estudantes de medicina para a elaboração de políticas preventivas.

A pesquisa de Caran et al. ${ }^{36}$ sobre o AMT na universidade apontou as mulheres como mais afetadas $(92,6 \%)$. Foram registradas exclusões de membros de comissões sem aviso prévio, fofocas, difamações, brincadeiras maliciosas, desvalorização profissional, agressões verbais, chantagens, intimidações em bancas de concursos públicos e utilização de trabalhos de outros para destaque pessoal. Houve relatos de envio de cartas anônimas para desqualificar o trabalho de colegas e ameaçá-los.

Em outra pesquisa com professores universitários, Rodrigues e Freitas ${ }^{40}$ entrevistaram 17 pessoas e analisaram os documentos de 6 processos trabalhistas relacionados ao AMT. As consequências desta violência atingem desde a vida pessoal e familiar até a carreira e as atividades de trabalho. Alguns entrevistados relataram aspectos negativos ligados ao salário e ao medo de perder o emprego. Para outros, houve aprendizagem e amadurecimento no processo de assédio. Os contextos sociais, culturais, políticos e históricos não devem estar afastados da compreensão da dinâmica do assédio no trabalho. Neste caso, as autoras mencionam a competitividade e as relações hierárquicas das instituições de ensino superior.

O AMT também foi analisado em estudo de caso com uma professora do ensino público ${ }^{37}$. A depoente relatou agressões verbais, exigências de tarefas não compatíveis com seu posto de trabalho e disseminação de calúnias sobre sua vida profissional e privada por parte de seu chefe. Os estudantes que se solidarizaram com ela sofreram retaliações. Durante a vivência do assédio, a professora foi acompanhada pelo serviço de saúde, que requereu sua transferência para outro local de trabalho. A gestão escolar, no entanto, negou a transferência. As repercussões em sua vida profissional e sua saúde foram intensas, com pensamentos suicidas, emagrecimento, baixa da autoestima, perda de memória etc. Os autores salientam as dificuldades impostas pela escola para que a professora resolvesse a sua remoção e as ações para que ela abandonasse o seu trabalho.

Outro estudo de caso com um servidor público, um bibliotecário, mostrou os efeitos do AMT na saúde do entrevistado ${ }^{41}$. A violência gerou insegurança, medo, depressão e distúrbios psíquicos com ideações suicidas. Foram confirmadas a degradação das condições de trabalho, o isolamento, a negação da comunicação, a manipulação, os abusos de poder, a retaliação aos colegas que confirmaram a violência sofrida pelo depoente etc.

Com relação ao AMT vivenciado por estudantes, há 3 pesquisas que merecem destaque. $\mathrm{O}$ estudo de Jacoby e Monteiro ${ }^{39}$ tem como tema o assédio moral em jovens universitários das áreas de psicologia, administração e contabilidade. A pesquisa foi realizada com 457 estudantes universitários de uma instituição privada de ensino, 69,1\% mulheres e 30,9\% homens; 98,6\% disseram ser heterossexuais, 1,2\% pretos e $3 \%$ mulatos. Houve altas taxas de AMT, nem sempre associadas à organização do trabalho. De modo geral, o assédio foi visto pelos entrevistados como natural e inerente às relações de trabalho. Outro estudo de Jacoby e Monteiro ${ }^{42}$ mostrou a insatisfação e o comprometimento do bem-estar em estudantes trabalhadores vítimas de AMT.

Pinto e Paula ${ }^{38}$ também apontaram a naturalização do AMT em estudo sobre a violência interpessoal em uma empresa júnior da área de administração e economia. As autoras criticam a qualificação dos assediadores como perversos e narcisistas e a passividade dos assediados(as). As principais contribuições do artigo estão na crítica à perspectiva psicologizante em relação aos assediadores e na abordagem contrária à naturalização do AMT.

\section{Discussão}

A maioria dos achados desta revisão integrativa corrobora a literatura ao reiterar as influências do AMT na saúde, na vida familiar e no desenvolvimento da carreira. Apoiados na literatura, Soares e Oliveira ${ }^{7}$ demonstram que a violência do AMT pode provocar ideações suicidas, e que as variáveis duração e frequência são importantes para o aparecimento desse comportamento. Dois estudos de caso, de uma professora ${ }^{37}$ e de um bibliotecário ${ }^{41}$, apontaram a presença de ideação suicida.

Nos casos de AMT, impede-se o direito ao exercício de um trabalho digno, ocasionando dor 
emocional, ansiedade, depressão, isolamento, medo de perder o emprego, estresse e doenças psicossomáticas ${ }^{44}$. Todas estas inflexões na vida e na saúde apontam para a necessidade de prevenção do AMT, tendo em vista garantir a dignidade e as condições de trabalho, elaborando estratégias efetivas para suprimir a violência ${ }^{4,5,8}$.

\section{Relações de gênero e poder no AMT}

As relações de poder entre homens e mulheres são consideradas por Lima e Sousa ${ }^{34}$ para entender a construção social do trabalho de enfermagem como predominantemente feminino e voltado ao cuidado. A partir do conceito de patriarcado, os autores buscam compreender a violência contra as mulheres, demonstrando as relações de poder e dominação entre homens e mulheres e entre a medicina e a enfermagem. Confirmando os achados de Lima e Sousa, o estudo de Rodrigo Marques et al. ${ }^{29}$ demonstrou que as mulheres foram mais acometidas pelas consequências do AMT entre residentes médicos e não médicos. Em outro estudo ${ }^{37}$, embora seus autores não mencionem as relações de gênero, nota-se que o AMT vivenciado por uma professora foi praticado por um homem, seu chefe.

Fontes e Carvalho ${ }^{28}$ encontraram resultados diferentes das pesquisas relatadas, apontando maior frequência de AMT cometido por assediadoras (enfermeiras). As autoras argumentam que esse fato pode ser explicado pelo maior número de mulheres na área do cuidado em saúde e pela necessidade constante delas terem seu trabalho reconhecido. A pesquisa de Cezar e Marziale ${ }^{25}$ mostra que não houve relação significativa entre profissão e AMT ou sexo e AMT. Sobre o número maior de homens que declararam ter sido vítimas de violência ocupacional, é importante indagar de que maneira as mulheres se percebem violentadas em seus ambientes, considerando a possibilidade de subnotificação dos casos de assédio.

Se, por um lado, os achados de Lima e Sousa ${ }^{34}$, Marques $^{29}$ et al. e Campos et al. ${ }^{37}$ reiteram a literatura $^{5,16}$ que aponta que as mulheres são mais suscetíveis à violência ocupacional, por outro, o estudo de Fontes e Carvalho ${ }^{28}$ mostra enfermeiras perpetrando o AMT. Pode-se concluir desses resultados que as múltiplas dimensões das relações de poder entre os gêneros e as hierarquias profissionais são centrais para entender o AMT em toda a sua complexidade, para além da relação entre homens e mulheres.

Embora Fontes e Carvalho ${ }^{28}$ tenham realizado o estudo apenas com enfermeiros(as), há de se considerar o desenvolvimento das profissões na área de saúde e as relações de poder. Na enfermagem, por exemplo, a história do cuidado humano e as hierarquias postas pela divisão social do trabalho engendram o saber fazer e as relações de poder. A divisão social do trabalho é perpetuada com a diferenciação entre enfermeiras de nível superior e de nível médio-técnico: "Nas relações da enfermeira com a equipe de enfermagem, verificam-se posturas diversas. Por vezes evidenciam-se atitudes autoritárias da primeira com suas subordinadas, nas quais se reproduz o estereótipo masculino de comando presente em suas relações com o poder-saber médico”45 (p. 399).

Kergoat $^{10}$, ao trazer à tona as relações sociais entre homens e mulheres, enfatiza a necessidade de se entender as suas complexidades. As relações de classe e "as sociais de sexo não funcionam de forma homogênea em todos os setores, nos diferentes níveis sociais" (p. 23). Portanto, para a autora, analisar as relações sociais a partir da perspectiva da dominação da mulher pelo homem por si só não é suficiente. Neste sentido, a noção de consubstancialidade é importante para entender as relações sociais, conflituosas, antagônicas e abstratas, opondo "grupos sociais em torno de uma disputa [enjeu]"46 (p. 95).

Entendendo estas relações como construídas socialmente, em um processo não estático, mas mutante e flexível ${ }^{9}$, é possível considerar sua importância para o entendimento do AMT para além da relação assediado(a) e assediador(a), homem e mulher. A divisão social do trabalho entre os grupos profissionais parece ser importante para as relações de poder e para a violência no trabalho.

Embora não tratem de relações de gênero, 3 pesquisas na área da educação ${ }^{36,37,40}$ se destacam ao considerar as relações de poder para compreender a complexidade do AMT. Esses estudos discutem o AMT em universidades e sua ligação com a competitividade, as hierarquias e as formas de violência entre pares. A importância da pesquisa de Caran et al. ${ }^{36}$ está nas múltiplas configurações do AMT, para além da via de mão única entre vítima e perpetrador, já que foram encontrados casos em que o professor foi ora assediador ora assediado.

Com isso, é possível afirmar que a complexidade das relações de poder no trabalho ultrapassa as hierarquias (professor e aluno, enfermeira e técnica de enfermagem), as relações de gênero (médicos e enfermagem) e as relações entre pares (colegas de trabalho). Considera-se ainda que, nos casos de AMT, há abusos de poder em detrimento do direito ao trabalho saudável e digno.

As relações de poder também podem estar relacionadas a questões geracionais, como apontam os estudos de Marques ${ }^{29}$ et al. (sobre residentes e médicos) e Lima e Sousa ${ }^{34}$ (sobre uma equipe de enfermagem). Nas duas pesquisas, os mais jovens foram os mais acometidos pelo AMT. Os achados confirmam 
as ideias de Elias e Scotson ${ }^{9}$, que consideram o poder como conflitivo e mutável, com variações de força ao longo do tempo. Os mais antigos podem se considerar superiores e depreciar o grupo mais jovem, reforçando a dominação daqueles que estão há mais tempo no poder. Os autores apontam ainda que as tensões relacionadas ao status e às hierarquias de um grupo social em relação a outro pode gerar angústias decorrentes do "preconceito" e da "discriminação"9 (p. 175).

Na pesquisa com enfermeiras de Fontes et al. ${ }^{30}$, foi apontado o problema de suportar as situações vividas no AMT, dada a necessidade de permanência no emprego. A entrada e a permanência das mulheres no mercado de trabalho formal é crescente ao longo dos últimos 50 anos $^{47}$, sendo que o crescimento do número de mulheres chefes de família ou que contribuem para a renda familiar na região metropolitana de São Paulo proporcionou um aumento considerável nos rendimentos, minimizando o empobrecimento ${ }^{48}$. Portanto, a necessidade financeira para muitas mulheres pode ser um dos fatores para permanecerem no emprego, aguentando situações de violência no trabalho. Para Hirigoyen ${ }^{5}$, as mulheres que cuidam de filhos sozinhas, trabalhadores em situações precárias e com poucas relações de solidariedade são as pessoas mais suscetíveis para o AMT.

A manutenção no emprego, mesmo em situações de AMT, também foi verificada com jovens estudantes. O crescente aumento do desemprego faz com que jovens permaneçam em situações de procura pelo primeiro emprego por um longo período, mas também contribui para que se submetam às condições de trabalho precárias. Em pesquisa portuguesa, a obtenção do diploma de nível superior não trouxe melhorias nas condições laborais dos estudantes ${ }^{49}$. Ou seja, é possível que esses jovens trabalhadores que foram assediados estão em busca da inserção no mercado e, ao mesmo tempo, estão galgando a qualificação profissional para a obtenção de empregos de melhor qualidade e de salários compatíveis com a formação. Com isso, o enfrentamento ao AMT não os fazem desistir do trabalho, pelo contrário, permanecem convivendo com a violência para a manutenção do emprego.

$\mathrm{Na}$ pesquisa de Rodrigues e Freitas ${ }^{40}$, com docentes universitários de instituições privadas de ensino, foi relatado o medo de perder o emprego. No entanto, nas situações de violência no trabalho, o medo é vivenciado também por homens e mulheres de outras profissões, como nos casos já citados dos servidores públicos, o bibliotecário ${ }^{41}$ e a professora $^{37}$. Esse medo é um dos efeitos deletérios do AMT e pode estar relacionado às ameaças aos trabalhadores(as). A literatura corrobora que quando uma pessoa sofre com a violência em seu ambiente de trabalho, as outras também sentem-se ameaçadas, com medo de que o mesmo aconteça com elas ${ }^{50}$.
A degradação das condições de trabalho como estratégia do assediador foi observada nas pesquisas com enfermeiros ${ }^{31}$ e trabalhadores da área de educação $^{36,41}$. Segundo Dejours ${ }^{51}$, ao longo da história o assédio sempre foi vivenciado pelos trabalhadores. Entretanto, o autor considera que o aumento das doenças decorrentes de perseguições deve-se sobretudo à diminuição das redes de solidariedade entre a classe trabalhadora, ocasionando o que chama de "patologias da solidão" (p. 17). Por isso, a organização, a gestão e as condições de trabalho são centrais para compreender o modo como a competividade e a busca pelas metas de desempenho podem contribuir para o aparecimento de doenças. Para a psicodinâmica do trabalho, as atividades laborais, importantes para a estruturação da psique e da criação, podem ser influenciadas pela degradação das condições de trabalho e o medo imposto pelo AMT, entre mulheres e homens, negros(as) e brancos(as).

Considera-se que as pesquisas sobre AMT analisadas neste artigo não permitiram entender plenamente como esta violência pode ser perpetrada e vivenciada de maneira diferente por homens e mulheres, bem como as relações de poder engendradas pelos grupos profissionais. A literatura evidencia que as mulheres são as mais afetadas por esse tipo de violência ${ }^{5,16,52,53}$. No entanto, a amostra da revisão integrativa pouco explorou a situação histórica e social do trabalho em saúde, a presença das mulheres na profissão e as relações de poder. Partindo da suposição das diferenças entre os gêneros nas situações do AMT, Souza e Ducatti $^{53}$ afirmam a necessidade de pesquisas que visem apreender as experiências de homens e mulheres, colocando-as como centrais para entender a complexidade do assédio no trabalho.

\section{O assédio sexual}

O assédio sexual foi constatado em 5 estu$\operatorname{dos}^{14,25,31,33,34}$, todos da área da saúde. A análise dos artigos permitiu compreender que o assédio moral pode se relacionar com o assédio sexual. Para a compreensão do assédio sexual e da violência contra a mulher, é preciso considerar a noção de patriarcado, que configura a submissão e subordinação da mulher ao homem ${ }^{54}$, e também o machismo, entendido como um conjunto de representações de um sistema ideológico que configura o sexismo: dominação, exploração, sujeição, inferioridade das mulheres e privilégios para os homens ${ }^{55}$.

O assédio sexual, relacionado a situações de conotação sexual sem consenso, interfere na integridade física e moral da trabalhadora e no desenvolvimento de sua carreira. Esta violência se manifesta em "anedotas ou expressões com conotações sexuais; contato físico não desejado; solicitação de favores sexuais; 
pressões para “"encontros”" e saídas; exibicionismo; voyeurismo; criação de ambiente pornográfico; abuso sexual e violação"56 (p. 13), além de chantagens. As profissões majoritariamente femininas estão mais propensas ao assédio sexual, como é o caso da enfermagem ${ }^{56}$, o que corrobora os achados desta revisão integrativa.

Considerado crime no Brasil, o assédio sexual deve ser entendido como violência de gênero, não sendo, portanto, um problema individual ${ }^{57}$. As mulheres são as mais expostas, principalmente aquelas das camadas populares e com menos de 25 anos $^{5}$. Em documento oficial da Organização Internacional do Trabalho, é expresso que o AMT está relacionado ao sexismo, pois as mulheres são mais assediadas no trabalho ${ }^{52}$.

No que se refere às imbricações entre assédio sexual e moral, as mulheres são as que mais sofrem, podendo ser vítimas de ameaças sexistas e machistas. Quando recusam situações com conotação sexual, são humilhadas e ficam constrangidas. Esta realidade é encontrada em todas as atividades profissionais e níveis hierárquicos: "as mulheres são simplesmente colocadas à margem ou assediadas e impedidas de trabalhar unicamente pelo simples fato de serem mulheres" ${ }^{5}$ (p. 102).

Outro ponto a ser discutido é a naturalização da violência, seja relacionada ao gênero ou no AMT. A educação sexista vivenciada pelas mulheres pode contribuir para que as humilhações sejam consideradas naturais ${ }^{53}$. Por outro lado, há de se considerar a permanência das mulheres em trabalhos precários e vulneráveis para o sustento da família, o que faz que elas suportem as situações de violência, como aponta a pesquisa francesa de Hirigoyen ${ }^{5}$.

\section{Raça/etnia e o AMT}

Na amostra desta revisão, somente Lima e Sousa ${ }^{34}$ abordaram a discriminação racial no contexto do AMT. Na área de educação, Caran et al. ${ }^{36}$ sinalizam a ausência de negros docentes na universidade, apontando a falta de possibilidades de ascensão à docência no ensino superior. Fontes et al. ${ }^{14}$, em análise da literatura, demonstram a carência de estudos que tenham o gênero e a raça como categorias centrais.

Todo assédio é discriminatório ${ }^{5}$, e quando relacionado à dimensão de raça e etnia pode haver intensificação da violência. Valette ${ }^{58}$, em estudo francês sobre o AMT e a organização do trabalho, verificou discriminações de todo tipo, ligadas a raça, sexo e posicionamento sindical de trabalhadores.

Considerando que os homossexuais, as mulheres e os negros são os que mais sofrem com a violência simbólica no mundo do trabalho ${ }^{59}$, é preciso integrar às investigações científicas as categorias de raça e gênero. A intolerância e a discriminação social no ambiente de trabalho afetam sobretudo os negros e pardos de camadas populares ${ }^{8}$.

\section{Conclusões}

Esta revisão da literatura analisou as produções sobre AMT considerando as dimensões de gênero, poder e raça.

A perspectiva do AMT para além das relações de dominação entre homens e mulheres foi observada somente em duas pesquisas da área da saúde, o que sugere que a classe social e as relações de poder entre os grupos profissionais devem ser consideradas em futuras investigações, assim como a contribuição de Kergoat ${ }^{12,46}$ sobre a consubstancialidade das relações sociais.

As pesquisas sobre violência no trabalho apontam a necessidade de investigações sobre o assédio sexual, vivenciado sobretudo pelas mulheres. A educação sexista, o machismo e a violência de gênero devem ser abordados em futuras pesquisas sobre AMT. Não foram encontrados estudos que analisassem diferenças do AMT segundo gênero.

Com relação a raça/etnia, apenas dois estudos analisaram sua ligação com o AMT. Um relata a discriminação racial, o outro, a ausência de negros como docentes no ensino superior. É importante que pesquisas abarquem esta dimensão para entender de que modo a violência no trabalho atinge diferentemente negros, pardos e brancos.

Em algumas pesquisas, a organização, as condições de trabalho e as relações de poder foram postas como centrais para entender as configurações do AMT. Nesse sentido, os referenciais teóricos e metodológicos da sociologia do trabalho são essenciais para compreender o trabalho de cuidado na saúde e na área de educação.

O AMT é considerado uma violência que atinge a integridade e a dignidade humana. É preciso entender como se constroem as estratégias coletivas de defesa da classe trabalhadora para minimizar o sofrimento. Como pontua Dejours ${ }^{60}$, o trabalho é criador, e pode favorecer ora os sofrimentos, ora os prazeres. Nessa dinâmica, a desestruturação da vida psíquica pode repercutir na saúde. São necessários programas e uma legislação específica para prevenir a violência ocupacional e a violência de gênero, o racismo e o abuso de poder. 


\section{Contribuições de autoria}

Andrade, C. B. contribuiu na definição do objeto e da metodologia, no levantamento, análise e interpretação das informações e na elaboração, revisão e aprovação da versão publicada. Assis, S. G, contribuiu na concepção da metodologia, na análise e interpretação das informações e na revisão e aprovação da versão publicada.

\section{Referências}

1. Antunes R, Praun L. A sociedade dos adoecimentos no trabalho. Serviço Soc Soc. 2015;(123):407-27.

2. Dejours C, Bègue F. Suicide et travail: que faire? Paris: Presses Universitaires de France; 2009.

3. OIT, CII, OMS, ISP. Directives générales sur la violence au travail dans le secteur de la santé [Internet]. Genève: BIT; 2002 [cited 2017 Feb 27]. Available from: http://www.ilo.org/public/libdoc/ ilo/2002/482744.pdf

4. Hirigoyen M-F. Assédio moral: a violência perversa no cotidiano. Rio de Janeiro: Bertrand Brasil; 2011.

5. Hirigoyen M-F. Mal-estar no trabalho: redefinindo o assédio moral. 8th ed. Rio de Janeiro: Bertrand Brasil; 2015.

6. Poilpot-Rocaboy G. Comprendre la violence au travail: le cas du harcèlement psychologique. Humanisme Entrep. 2010;296(1):9.

7. Soares A, Oliveira JA. Assédio moral no trabalho. Rev Bras Saude Ocup. 2012;37(126):195-202.

8. Barreto M, Heloani R. Violência, saúde e trabalho: a intolerância e o assédio moral nas relações laborais. Serviço Soc Soc. 2015;(123):544-61.

9. Elias N, Scotson JL. Os estabelecidos e os outsiders: sociologia das relações de poder a partir de uma pequena comunidade. Rio de Janeiro: Jorge Zahar; 2010.

10. Kergoat D. Relações sociais de sexo e divisão sexual do trabalho. In: Lopes MJM, Meyer DEE, Waldow VR, editors. Gênero e Saúde. Porto Alegre: Artes Médicas; 1996. p. 19-27.

11. Hirata H, Kergoat D. Novas configurações da divisão sexual do trabalho. Cad Pesqui. 2007;37(132):595-609.

12. Kergoat D. O cuidado e a imbricação das relações sociais. In: Abreu, ARP, Lombardi, MR, editors. Gênero e trabalho no Brasil e na França: perspectivas interseccionais. São Paulo: Boitempo; 2016. p. 17-26.

13. Bruschini C, Lombardi MR. Mulheres e homens no mercado de trabalho brasileiro: um retrato dos anos 1990. In: Maruani M, Hirata H, editors. As novas fronteiras da desigualdade: homens e mulheres no mercado de trabalho. São Paulo: Senac; 2003. p. 323-56.

14. Fontes KB, Pelloso SM, Carvalho MDB. Tendency of the studies on moral harassment and nurses. Rev Gaúcha Enferm. 2011;32(4):815-22.

15. Molinier P. Prévenir la violence: l'invisibilité du travail des femmes. Travailler. 1999;73-86.
16. Heloani R. Assédio moral: a dignidade violada. Aletheia. 2005;(22):101-8.

17. Bobroff MCC, Martins JT. Assédio moral, ética e sofrimento no trabalho. Rev Bioét. 2013;21(2):251-8.

18. Gaignard L. Racisme et travail. Travailler. 2006;16(2):7-14.

19. Machado MH, Oliveira ES, Moyses NMN. Tendências do mercado de trabalho em saúde no Brasil. In: Pierantoni CR, Dal Poz MR, França T, editors. $\mathrm{O}$ trabalho em saúde: abordagens quantitativas e qualitativas. Rio de Janeiro: Cepesc; IMS/Uerj; ObservaRH, 2011. p. 103-16.

20. Dieese. Transformações recentes no perfil do docente das escolas estaduais e municipais de educação básica: uma análise a partir dos dados da PNAD. São Paulo: Dieese; 2014.

21. Botelho LLR, Cunha CCA, Macedo M. O método da revisão integrativa nos estudos organizacionais. Gest e Soc. 2011;5(11):121-136.

22. Souza MT, Silva MD, Carvalho R. Revisão integrativa: o que é e como fazer. Einstein. 2010;8(1):102-6.

23. Hagopian EM, Freitas GF, Costa KS. É possível discutir o assédio moral na enfermagem? Cult Cuid. 2016;20(45):117-25.

24. Moher D, Liberati A, Tetzlaff J, Altman DG. Principais itens para relatar revisões sistemáticas e meta-análises: a recomendação PRISMA. Epidemiol e Serviços Saúde. 2015;24(2):335-42.

25. Cezar ES, Marziale MHP. Problemas de violência ocupacional em um serviço de urgência hospitalar da cidade de Londrina, Paraná, Brasil. Cad Saúde Pública. 2006;22(1):217-21.

26. Xavier ACH, Barcelos CRV, Lopes JP, Chamarelli PG, Ribeiro SS, Lacerda LS, et al. Assédio moral no trabalho no setor saúde no Rio de Janeiro: algumas características. Rev Bras Saude Ocup. 2008;33(117):15-22.

27. Villaça FM, Palacios MM. Concepções sobre assédio moral: bullying e trote em uma escola médica. Rev Bras Educ Med. 2010;34(4):506-14.

28. Fontes KB, Carvalho MD de B. Variáveis envolvidas na percepção do assédio moral. Rev Latino-Am Enfermagem. 2012;20(4):761-8.

29. Marques RC, Martins-Filho ED, Paula G, Santos RR. Assédio moral nas residências médica e não médica de um hospital de ensino. Rev Bras Educ Med. 2012;36(3):401-6. 
30. Fontes KB, Santana RG, Pelloso SM, Carvalho MD. Factors associated with bullying at nurses' workplaces. Rev Latino-Am Enfermagem. 2013;21(3):758-64.

31. Cahu GR, Costa SF, Pinto Costa IC, Souza Batista PS, Vidal Batista JB. Moral harassment experienced by nurses in their workplace. ACTA Paul Enferm. 2014;27(2):151-6.

32. Nelson SA, Azevedo PR, Dias RS, Sousa SMA, Carvalho LDP, Silva ACO, et al. The influence of bullying on the wellbeing of Brazilian nursing professionals. Public Money Manag. 2014;34(6):397-404.

33. Andrade CG, Leão JDM, Costa ICP, Brito FM, Santos KFO, Costa SFG. Assédio moral na atenção básica segundo os profissionais de enfermagem. Trab Educ e Saúde. 2015;13:77-90.

34. Lima GHA, Sousa SMA. Violência psicológica no trabalho da enfermagem. Rev Bras Enferm. 2015;68(5):817-23.

35. Canen AG, Canen A. Multicultural leadership: the costs of its absence in organizational conflict management. Int J Confl Manag. 2008;19(1):4-19.

36. Caran VCS, Secco IAO, Barbosa DA, Robazzi MLCC. Assédio moral entre docentes de instituição pública de ensino superior do Brasil. Acta Paul Enferm. 2010;23(6):737-744.

37. Campos ICM, Serafim Ada C, Custódio KV, Silva L, Cruz RM. Moral harassment of public schools teachers. Work. 2012;41(1):2001-7.

38. Pinto RAB, Paula APP. Do assédio moral à violência interpessoal: relatos sobre uma empresa júnior. Cad EBAPE.BR. 2013;11(3):340-55.

39. Jacoby AR, Monteiro JK. Mobbing of working students. Paid Ribeirão Preto. 2014;24(57):39-47.

40. Rodrigues M, Freitas ME. Assédio moral nas instituições de ensino superior: um estudo sobre as condições organizacionais que favorecem sua ocorrência. Cad EBAPE.BR. 2014;12(2):284-301.

41. Guimarães CA, Cançado VL, Lima RJC. Workplace moral harassment and its consequences: a case study in a federal higher education institution. Rev Adm São Paulo. 2016;51(2):151-64.

42. Jacoby AR, Monteiro JK. Assédio moral em estudantes trabalhadores e sua relação com o bemestar no trabalho. Interaçao Psicol. 2016;20(3):319-29.

43. Minayo MC. Relaciones entre procesos sociales, violencia y calidad de vida. Salud Colect. 2005;1(1):69-78.

44. Murray JS. Workplace bullying in nursing: a problem that can't be ignored. Medsurg Nurs. 2009;18(5):273.

45. Pinto E, Fabbro SMRC, Heloani R. O trabalho de enfermeiras e guardas municipais. InterfaceComunic Saude Educ. 2009;13(31):395-407.

46. Kergoat D. Dinâmica e consubstancialidade das relações sociais. Novos Estud Cebrap. 2010;(86):93-103.
47. Guimarães NA, Brito MMA. Mercantilização no feminino: a visibilidade do trabalho das mulheres no Brasil. In: Abreu, ARP, Lombardi, MR, editors. Gênero e trabalho no Brasil e na França: perspectivas interseccionais. São Paulo: Boitempo; 2016. p. 71-82.

48. Montali L. Provedoras e co-provedoras: mulherescônjuge e mulheres-chefe de família sob a precarização do trabalho e o desemprego. Rev Bras Estud Popul [Internet]. 2006 [cited 2017 Set 11]. Available from: http://www.scielo.br/pdf/rbepop/ v23n2/a03v23n2

49. Sousa LN. Emprego e trajetórias profissionais: o caso dos diplomados do Instituto Superior Politécnico de Viseu. Sociol Rev Fac Let Univ Porto. 2012;23:149-68.

50. Freire PA. Mobbing and the worker's mental health. Trab Educ e Saúde. 2008;6(2):367-380.

51. Dejours C. Avant-propos para a edição brasileira. In: Lancman S, Sznelwar LI, editors. Christophe Dejours: da psicopatologia à psicodinâmica do trabalho. Rio de Janeiro: Editora Fiocruz; Paralelo 15; 2004. p. 15-22.

52. Renaut A. Moral harassment: work organization to blame? In: Violence at work. Genebra: ILO; 2003. p. 1-6.

53. Souza TMS, Ducatti I. Dividir para reinar: las relaciones de género en el acoso moral en el trabajo. Salud Trab Maracay. 2014;22(2):141-50.

54. Saffioti H. Violência doméstica ou a lógica do galinheiro. In: Kupstas, M. Violência em debate. São Paulo: Moderna; 1997. p. 39-57.

55. Borges CA. Machismo. In: Fleury B, Meneghel SN, editors. Dicionário feminino da infâmia: acolhimento e diagnóstico de mulheres em situação de violência. Rio de Janeiro: Editora Fiocruz; 2015. p. 213-5.

56. Dias I. Violência contra as mulheres no trabalho: o caso do assédio sexual. Sociol Probl e Práticas. 2008;(57):11-23.

57. Souza TMS. Assédio moral e assédio sexual: interfaces. InterfacEHS [Internet]. 2011 [cited 2017 Mar 23];3(3). Available from: http://www3. sp.senac.br/hotsites/blogs/InterfacEHS/wp-content/ uploads/2013/07/art-2-2008-3.pdf

58. Valette J-C. Harcèlement moral: violence ou domination? Santé mentale au travail et action. In: Dejours C, editor. Conjurer la violence: travail, violence et santé. Paris: Payot \& Rivages; 2011. p. 309-24.

59. Carrieri A de P, Aguiar ARC, Diniz APR. Reflections on the desiring individual and suffering at work: workplace bullying, symbolic violence, and the homosexual. Cad EBAPE.BR. 2013;11(1):165-80.

60. Dejours C. A loucura do trabalho: estudo de psicopatologia do trabalho. São Paulo: Cortez; 1992. 